\title{
On the Reduction of Heat Island Phenomena by Various Types of Rooftop Planting
}

\author{
Park Chan Jin
}

\begin{abstract}
The temperature distributions of various rooftop region were investigated by measuring major temperature in several kinds of roof-planting locations during day time in Incheon city. From the investigations, the temperatures were very high in concrete material, but temperatures were decreased in the vegetable pots, flower beds in the same locations with the increase of planting areas. Theoretical analysis were made to explain those results.
\end{abstract}

Index Terms-Vegetable pots, rooftop-planting, temperature.

\section{INTRODUCTION}

Global warming has caused heat island effect more strong with the increase of surface temperature of the earth. The heat island effect in metropolitan cities were measured by many researchers [1], [2], and strong typhoon and various cold weather in winter might be the most threatening factors which must be solved for the safety of our living.

The various methods of mitigation for heat island phenomena in downtown regions were tested for the utilization of empty concrete space of building rooftops such as a dwarfed potted plant or flower spots to form various green regions. In this study the temperature variation of different locations were studied and the results were discussed.

\section{EXPERIMENTAL}

In this study we have chosen all locations as rooftop regions such as citizen centers and buildings with gardens of various green sectors for the measurement areas. Different ten locations of temperature measurements in downtown city were selected as in Fig. 1.

To calculate temperature variations three points were selected at one location and temperature with humidities, and they were measured with digital thermometers.

Measurements were started at ten o'clock A.M. and finished at five o'clock P.M. in every one hour. Arithmetic averages of three points were used to estimate mean temperatures and humidities from each locations as shown in our previous study [3]. In this study, the methods of reducing surface temperatures by reducing concrete surface covered with green areas such as a dwarfed potted plant or flower spots as in Fig. 1.

Manuscript received April 26, 2013; revised July 16, 2013.

Park Chan Jin is with the School of Urban \& Environmental Engineering, Incheon National University, Incheon, Korea (email:cjpark@incheon.ac.kr).

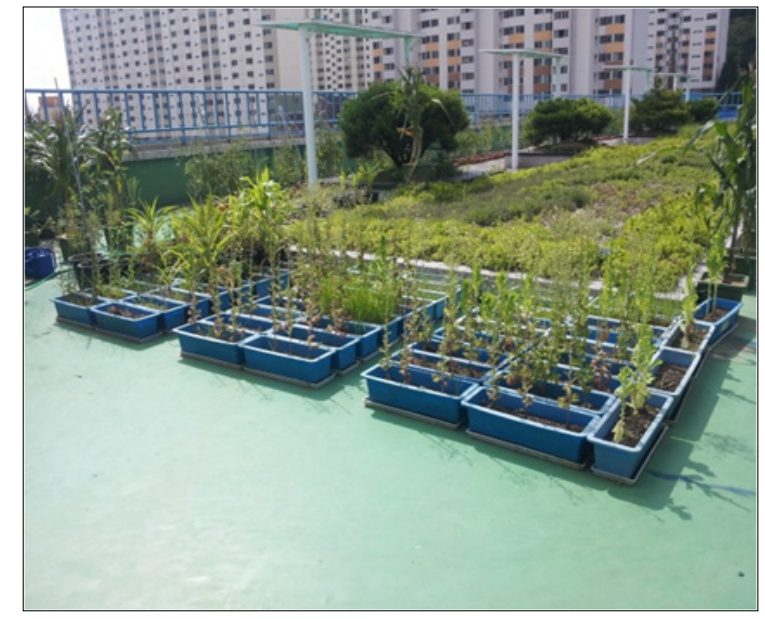

Fig. 1. Various rooftop green planting to cool the surface of buildings (Type - A)

The temperature differences between green area \& concrete or asphalt and soil area were compared to suggest effective methods of mitigating the heat island phenomena in the downtown regions.

\section{RESULTS AND DISCUSSIONS}

From the measurements, the variation of ambient temperatures of concrete area showed slight rapid increase from the morning to the one and a half o'clock in the afternoon, and it could be explained that these are the main reasons of thermal generation to the atmosphere. In clear weather, the difference of temperature between green region and bare concrete region showed almost the same temperature drops.

Most important factors for temperature rise is the absorptivity, heat capacity and reflectivity of heat sinks and radiation angles from solar radiation to earth's surfaces [4], [5].

Therefore the surface which can be changed to grass, tree and flower gardens or park is very important for minimizing heat island phenomena in the downtown regions.

In our study, the vegetable garden was the lowest, and the shade, sunny spots in the temperature. The vegetable garden was 3.3 degree low than sunny spots, and was 1.7 degree than the shade. And from the experiment, it could be known that as the green area becomes larger, the temperature profile shows almost no change during sunlight time. Fig.2 and 3 show the effect of green-roof garden size on temperature elapse.

The temperature increase of only concrete region was highest to 40 at 10:30 $\mathrm{AM}$, and maximum temperature drop was 11 degree in Centigrade in the rooftop of library building. 


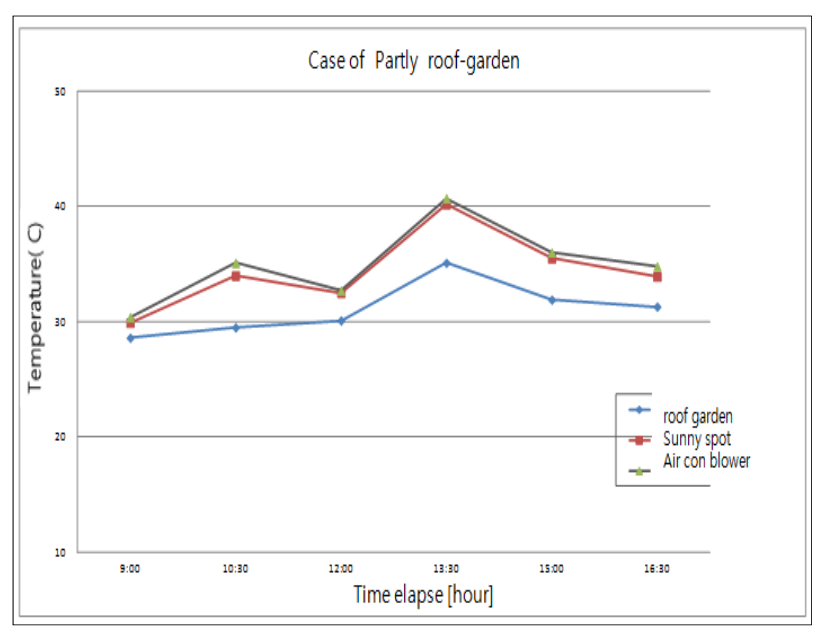

Fig. 2. Temperature distribution in partly roof-garden

From the analysis of our study, the temperature rise was very inconsiderable in the green regions in all kinds of green plants.

Temperatures were measured from ten o'clock in the morning to five o'clock in the afternoon as explained earlier. In central park with large scale of trees, ponds and bare earth surfaces, temperature rise with the time elapse was not high until three o'clock in the clean day. But temperatures in the values about twelve to one o' clock in the same clean day. It can be found that the effect of temperature decreasing is higher as the green area is larger in the roof surface area in the building. Therefore as treepots or flowerpots are placed on the concrete surface of building rooftop, the cooling phenomena can be fairly large although the total temperature drop is small compared to rooftop garden.
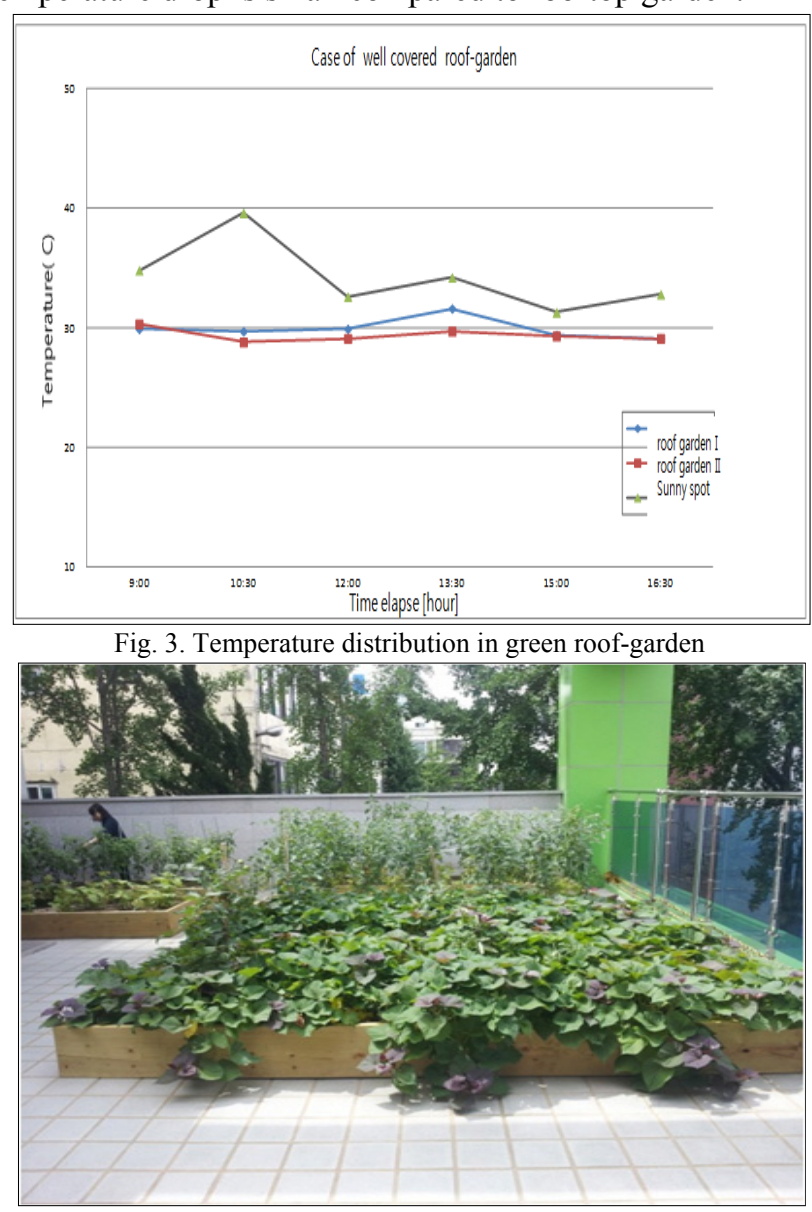

Fig. 4. Picture of well designed green roof-garden (Type-B)
Our team has been measured the effect of reducing temperature rise for various types of rooftop planting for many years.

The obvious facts are considerable temperature decrease due to green plants with many leafs. The best effective method of cooling rooftop temperature is to build complete rooftop garden by covering complete green plants. Fig.4 and 5 shows two types of rooftop plantings.

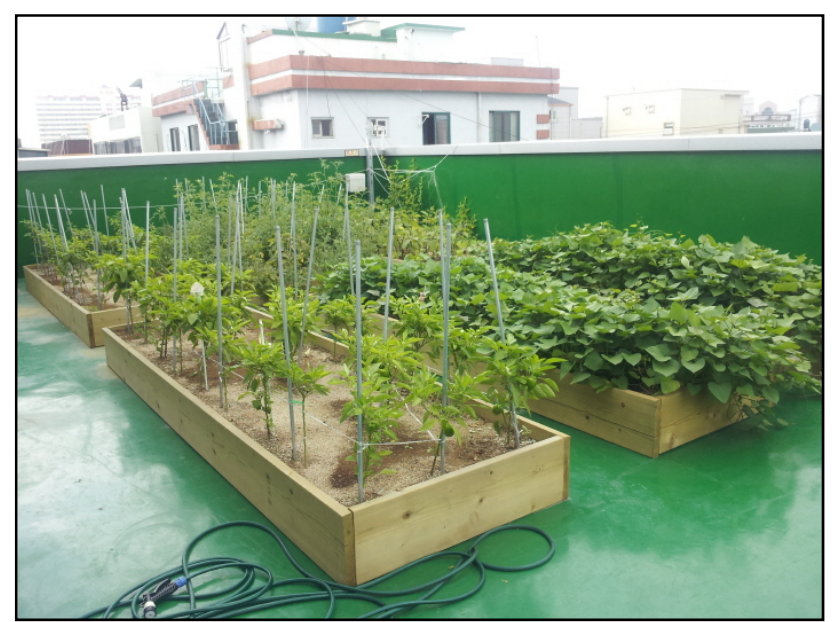

Fig. 5. Picture of portable roof-garden facility (Type-C)

But complete rooftop planting needs high cost of construction, and water-proof situation for the safety of buildings. But it is certain that the effect of cooling surface is more strong in the rooftop situation than in the ground one. And the strong cooling phenomena is due to the disturbance effect of various leaves of green plants for the solar radiations.

From the measurement, it could be found that the feeding of water to the green plants in the morning has another effect for the cooling effect of rooftop surface in the monitoring area. The maximal temperature differences are roughly eleven or twelve degree between the bare concrete rooftop and well-designed green park of rooftop. Fig. 6 and 7 shows temperature profiles with various locations.

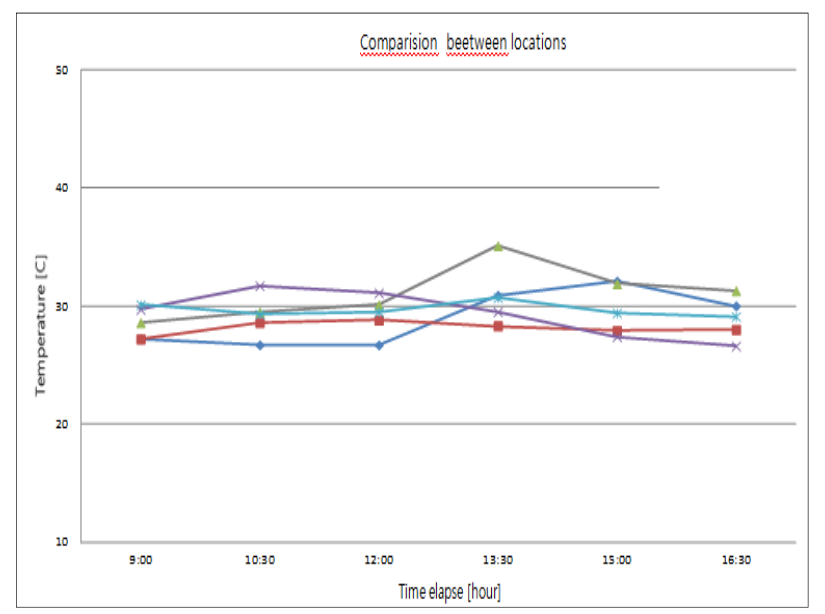

Fig. 6. Comparison of temperature profiles with various locations

Therefore the heat island phenomena of urban area could be reduced with the construction of green area such as rooftop green garden or portable roof-garden In view of heat transfer phenomena the radiative energy transfer to rooftop surface could be expressed as the following equation (1) $[6]$. 


$$
\mathrm{q} / \mathrm{A}=\sigma \Delta \mathrm{T}^{4}
$$

This equation is expressed as the Stefan-Boltzmann's law and radiant energy transmitted is very important factors in heat transfer phenomena. Stefan-Boltzmann constant is dependent on various conditions of heat sinks such as many shapes of plant leaves and angles, height of flowers and absorptivity, emissivity and reflectivity of heat sinks. Fig. 8 shows another type of portable roofgarden, and Fig. 9 shows one kind of vegetables in the roof-garden facility.

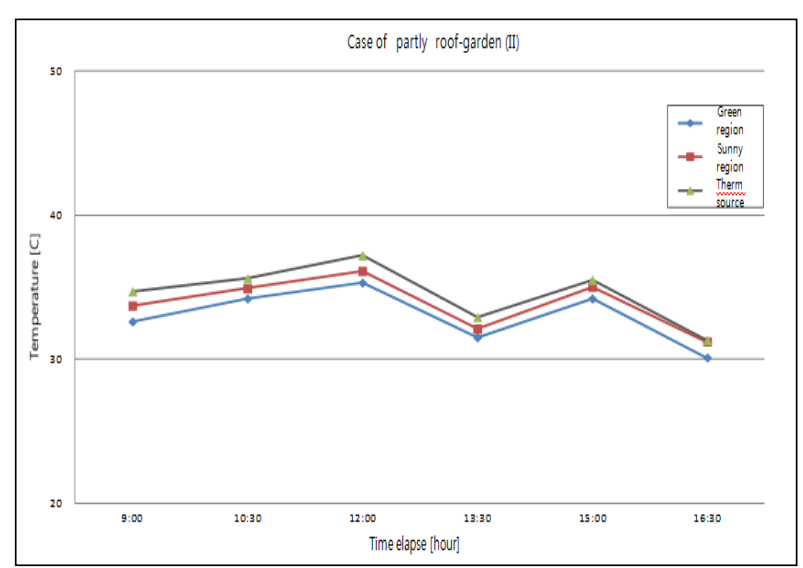

Fig. 7. Comparison of temperature profiles with various locations

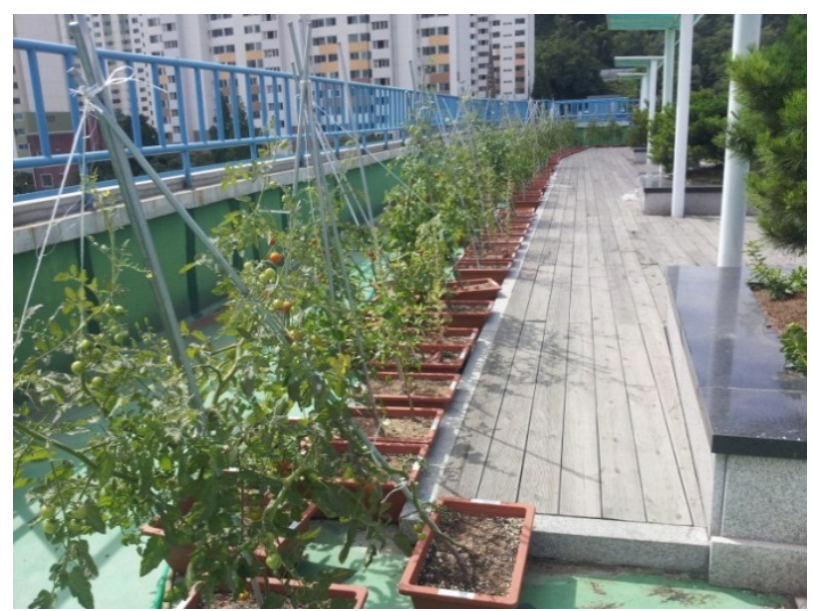

Fig. 8. Picture of portable roof-garden facility (Type- D)

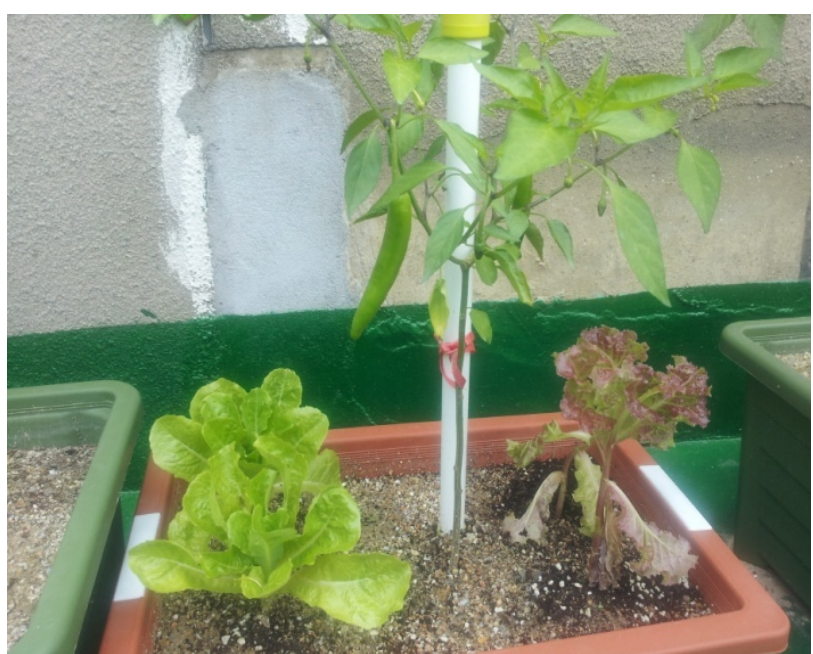

Fig. 9. Picture of vegetables in the roof-garden facility
Global warming phenomena have caused many extraordinary phenomena in weather which has caused many disasters and unexpected happenings. Therefore many kinds of efforts to overcome global warming must be continued [7], [8]

\section{CONCLUSIONS}

Nowadays global warming phenomena becomes larger and unexpected disaster of weather happens in our village of earth. Therefore, many kinds of efforts must be proceeded to cool down the earth's warming symptoms in recent years.

As our many studies concerning rooftop garden can be seen, the increase of green region can have cooling action of buildings and the rooftop region in the building can be the green more easier with tree pots and flower pots.

There are many possible sources of reducing the heat island phenomena in city. The first one is the green plants like rooftop garden, and second one is river or small rivulet, ponds like water sources.

The research on the reduction of heat island effects with the reduction of greenhouse gas will be continued with the cooperation of Nam-gu Agenda 21 of Incheon.

\section{ACKNOWLEDGEMENT}

The author thanks the Incheon National University of for supporting this research.

\section{REFERENCES}

[1] L. Gartland, Understanding and Mitigating Heat in Urban Areas, Earthscan, pp.100-102, 2008.

[2] A. H. Rosenfeld, et al., "Cool communities: strategies for heat island mitigation and smog reduction," Energy and Buildings, vol. 28, pp. 51-62, 1998.

[3] C. J. Park, "On the improvement of heat island phenomena by rooftop planting in downtown regions," in Proceedings of ICEAE, pp.105-107, 2012.

[4] S. Makoto, O. Kazumasa, and M. Takashi, "The measurement on the rooftop greening and radiational environment (Part 1)," in Proceedings of JSES/JWEA Joint Conference, pp. 137-140, 2003.

[5] F. Wilmers, "Effects of vegetation on urban climate and buildings," Energy and Buildings, vol. 15, pp. 507-514, 1990.

[6] J. P. Holman, Heat transfer, Mcgraw-Hill, pp. 379-380, 2009.

[7] Y. H. Yoon et al., "Current States of Rooftop Greening in Japan," J. Korean Society for People, Plants and Environment, pp.27-32, 2006.

[8] H. J. Yoon et al., "Temperature Monitoring of Planting Models for the Extensive Rooftop Greening," J. Korea Institute of Ecological Architecture and Environment, pp. 58-59, 2013.

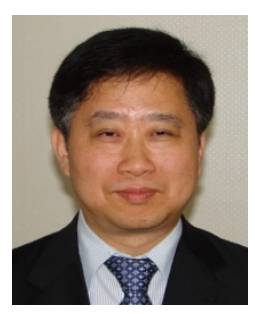

Park Chan Jin graduated from Korea University in Chemical Engineering and got Master and Ph.D Degree in 1989 at same university. Major fields of study nowadays are air pollution control, global warming mitigation and odor management technology. He is now full professor of the department of environmental engineering in Incheon National University. He is member of Korea Institute of Chemical Engineering, Korean Society of Odor Research and Engineering. He has got academic awards in his major fields of environmental and odor researches. 